\title{
GPS measurement of active strains across the Apennines
}

\author{
ENRICO SERPELLONI $\left({ }^{1}\right)$, MARCO ANZIDEI $\left({ }^{2}\right)$, PAOLO BALDI $\left({ }^{3}\right)$, GIUSEPPE CASULA $\left({ }^{1}\right)$ \\ and ALESSANDRO GALVANI $\left({ }^{2}\right)$ \\ (') Istituto Nazionale di Geofisica e Vulcanologia - Centro Nazionale Terremoti, Sede di Bologna, Italy \\ ${ }^{(2)}$ Istituto Nazionale di Geofisica e Vulcanologia - Centro Nazionale Terremoti, Roma, Italy \\ $\left(^{3}\right)$ Dipartimento di Fisica, Settore di Geofisica, Università degli Studi di Bologna, Italy
}

\begin{abstract}
Geodetic data are providing a new prospective in studying active tectonic processes that are occurring in peninsular Italy. In this paper we use a recently published GPS velocity solution, obtained by merging a data set of permanent and non-permanent networks spanning the 1991-2002 time interval, to provide new quantitative constraints of the active deformation rates across the Apennines Chain and the Calabrian Arc. The velocity field, given with respect to a fixed Eurasian frame, has been used to compute horizontal strain-rates within polygonal regions that connect and include geodetic stations, and to draw velocity cross sections along 5 different profiles through this region. The computed strain-rates provide a picture of the regional deformation field, which is in agreement with other seismological and geological data, and show that the Apennines are mainly extending in a SW-NE direction, while in Calabria extension is NW-SE oriented. Indications of active shortening are present only in the outer Northern Apennines. The velocity profiles across the Northern and Southern Apennines, along the Tyrrhenian Sea and Calabria, provide a quantitative measurement of the active extension and shortening rates, which are taking up at a more local scale.
\end{abstract}

\subsection{INTRODUCTION}

The Italian region is located in the Central Mediterranean, within a broad plate boundary zone. The complex tectonic setting of the Central Mediterranean (fig. 1.1) and the Neogene-Quaternary evolution of the present-day stress and strain fields are considered a direct result of the interplay among two main tectonic plates, Africa and Eurasia (Dewey et al., 1989; Mantovani et al., 1996), with an important role played by minor plates and smaller crustal blocks (i.e. Adria). Along the Italian Peninsula the present-day tectonic setting is particularly complex since different processes are acting at the same time and in close proximity. These processes include the northward indentation of the Adriatic microplate beneath the Southern Alps, the flexure of the continental Adriatic lithosphere below the Apennines, and the subduction/sinking of the Ionian lithosphere below the Calabrian Arc. This complexity is reflected in a strongly variable stress field (Montone et al., 1999). In this paper we focus on the Apennines Chain that, together with the Calabrian Arc and the Sicilian Maghrebides, constitutes a pile of Adria/Africa verging nappes detached from the Adria and Africa continental margins, overlaid by Tethyan ophiolitic units and by continental-basement nappes.

The present-day seismicity in the Central Mediterranean region mainly occurs along the principal mountain ranges: the Alps, the Apennines and the Dinarides. But despite the overall convergence within the Mediterranean, the present tectonic regime of peninsular Italy is dominated by extension perpendicular to the axis of the Apennines Chain (Anderson and Jackson, 1987; Westaway, 1992; Montone et al., 1999; Viti et al., 2001). This is in agreement with the distribution of historical and in- 


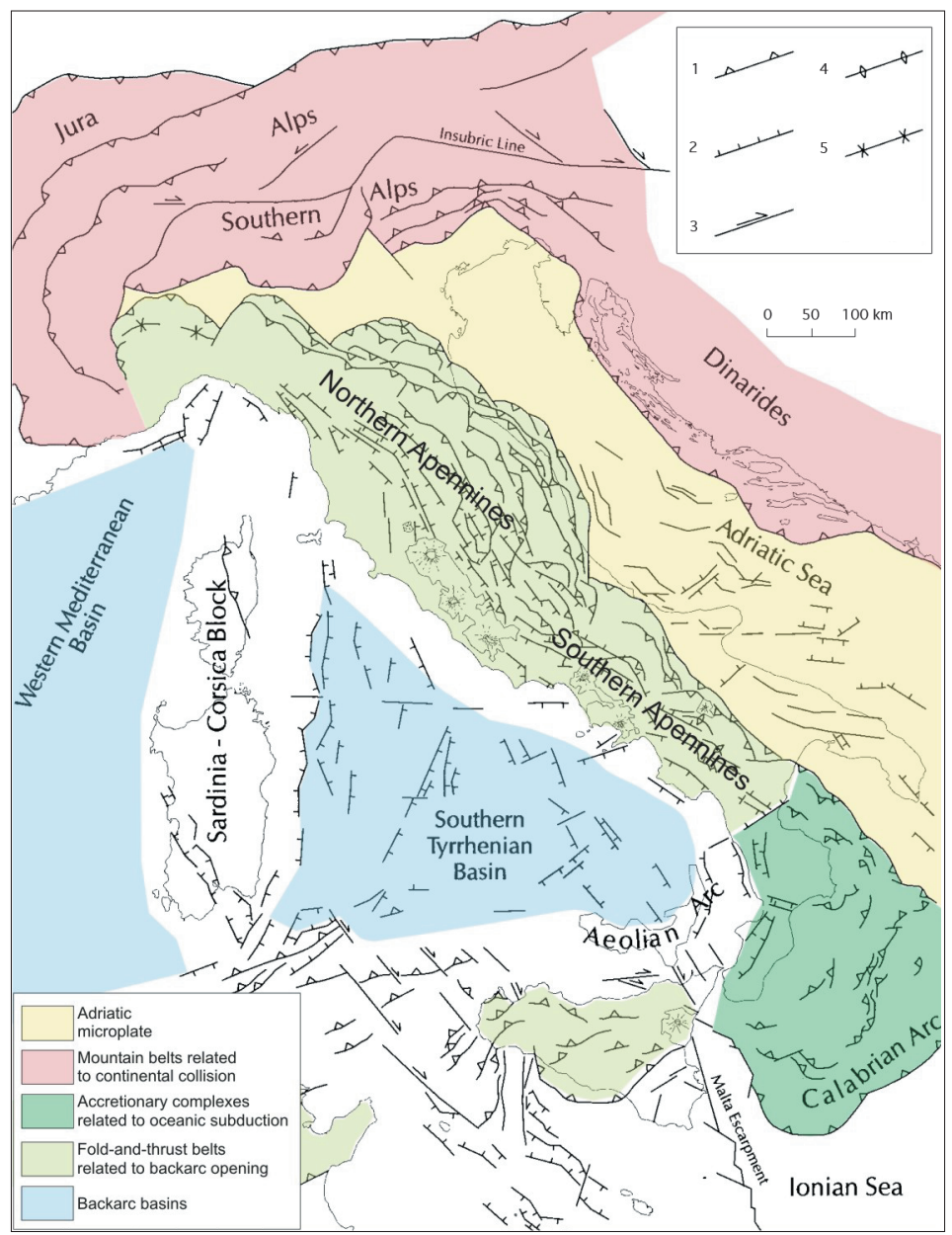

Fig. 1.1. Simplified structural map of the Central Mediterranean region showing the main tectonic domains (after Meletti et al., 2000): 1 - thrusts; 2 - normal faults; 3 - strike slip faults; 4 - Pliocene-Quaternary anticlines; 5 - Pliocene-Quaternary synclines.

strumental seismic, geological/geophysical observations and normal faults striking about parallel to the Apenninic Chain (Valensise and Pantosti, 2001a,b). Compressive tectonics now seems to be restricted only to a narrow band along the Northern Apenninic front (Selvaggi and Amato, 1992; Montone and Mariucci, 1999; Pondrelli et al., 2002).

Estimates of the deformation rates along the Apennines have been obtained from summation of seismic moment tensors of recent and historical earthquakes, and range from $0.3 \mathrm{~mm} / \mathrm{yr}$ in the Northern Apennines to $2.0 \mathrm{~mm} / \mathrm{yr}$ in the Central and Southern Apennines (Selvaggi, 1998), although earlier evaluations provided values ranging from $3 \mathrm{~mm} / \mathrm{yr}$ up to $10 \mathrm{~mm} / \mathrm{yr}$ (Westaway, 1992). These estimates, however, suffer from different choices of seismic catalogues and $M_{s}-M_{o}$ relationships. The contemporary extension of the Apennines has been recently estimated by GPS and terrestrial geodetic 
data (Hunstad and England, 1999; D’Agostino et al., 2001; Serpelloni et al., 2001; Hunstad et al., 2003; Anzidei et al., 2005), which suggest that an extension of about 3-6 mm/yr takes place across the Apennines, without giving clear information on the localization of the strain respect to the region of active faulting.

The low deformation rates observed in the study region would require an accurate estimate of crustal deformation parameters that can be obtained through the use of continuous GPS stations. On the other hand, an exhaustive description of the deformation pattern of this high tectonically fragmented zone needs a high spatial resolution, that is currently possible only by the use of a number of non-permanent stations. The combination of permanent and non-permanent GPS networks into a well defined common reference frame is a fundamental aspect of each study that would attempt to study active tectonics in Italy.

In this paper we use the velocity field reported in Serpelloni et al. (2005), who combined GPS observations from continuous and campaign networks at local, regional and global scales, to provide a new quantitative direct measurement of active strains along the Apennines Chain and Calabria. We used station velocities to compute strain-rates within polygonal regions that connect and include GPS stations. These strain-rates provide the regional strain field, and average values of active extension or shortening. A more detailed analysis of the deformation rates across the Apennines Chain has been performed by constructing five velocity profiles: two across the Northern Apennines, two across the Southern Apennines, and one along the Tyrrhenian Sea, through Calabria.

\subsection{GPS DATA PROCESSING}

We analyzed observations coming from GPS surveys performed in the 1991-2001 time span (for more details see Serpelloni et al., 2001, 2002, 2005). GPS observations from more than 80 non-permanent stations and more than 40 permanent stations have been combined into a uniform and selfconsistent velocity field, realized into a common reference frame.

The entire GPS data-set has been analyzed using the GAMIT/GLOBK software (Herring, 2000; King and Bock, 2000), following a distributed session strategy (Blewitt et al., 1993), through the quasi-observation approach (Dong et al., 1998, 2002). We used the GAMIT software to reduce GPS observations and the GLOBK software to combine daily loosely constrained solutions with global and regional solutions provided by SOPAC (http://sopac.ucsd.edu). Each daily (loosely constrained) combined solution has been treated as a quasi-observation (Dong et al., 1998), and we obtained station position time series in a common reference frame by constructing a network constrained solution using a set of globally and regionally distributed IGS stations (for more details see Dong et al., 2002). A seven parameters transformation has been applied to provide each solution in the ITRF2000 (Altamimi et al., 2002). An exhaustive description of the data analysis is reported in Serpelloni et al. $(2002,2005)$. We used a robust-fit algorithm, embedded in the QOCA software, to compute the horizontal velocities from the position time-series. To obtain realistic velocity errors we adopted an empirical model that includes white, flicker and random-walk noise (Mao et al., 1999; Dixon et al., 2000). The weighted root mean squared residuals from position time series, for each individual station, was used to scale these contributing processes. Figure 1.2 shows the residual velocities (error ellipses at $95 \%$ confidence level) with respect to the Eurasian fixed frame described in Serpelloni et al. (2005).

\subsection{Velocity AND STRAIN-RATE FIELDS IN THE APENNINES}

To study the regional-scale features of the geodetic horizontal strain-rate field along the Apennines, we divided the network into several polygonal subnetworks (fig. 1.3) that fit, as much as pos- 


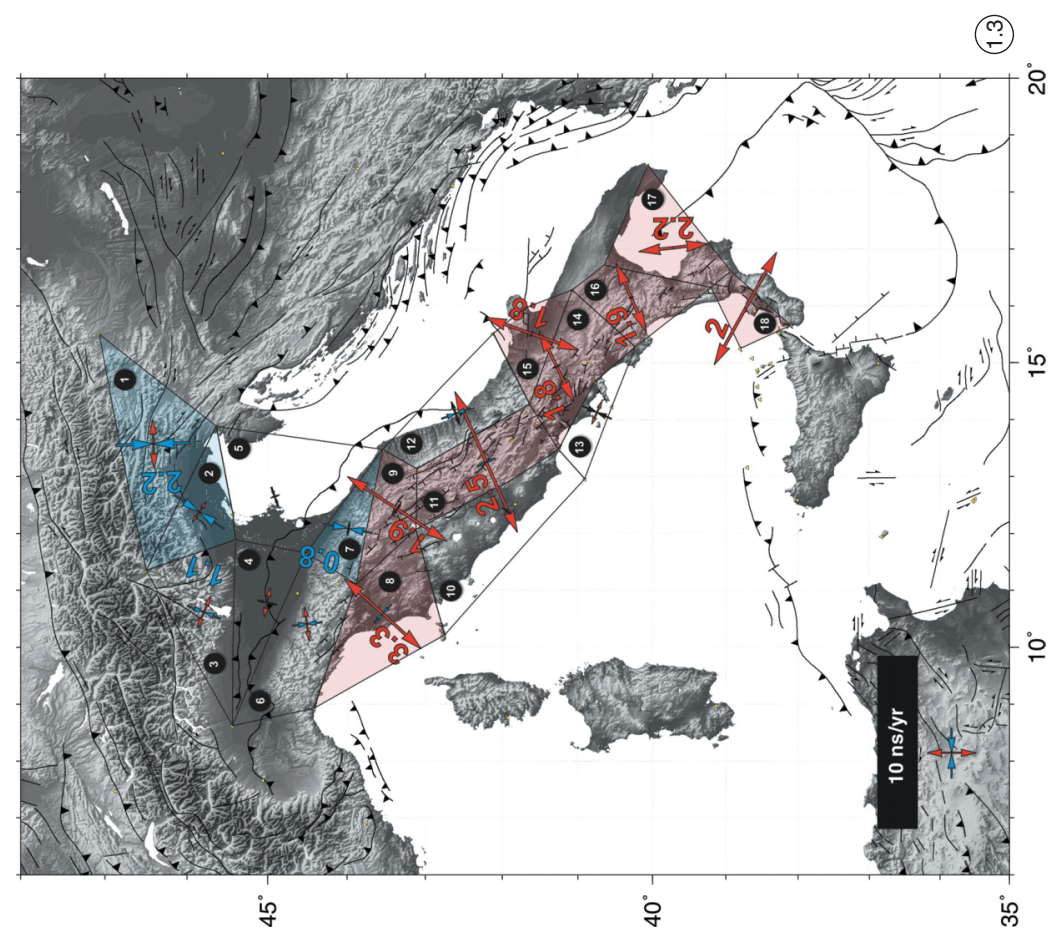

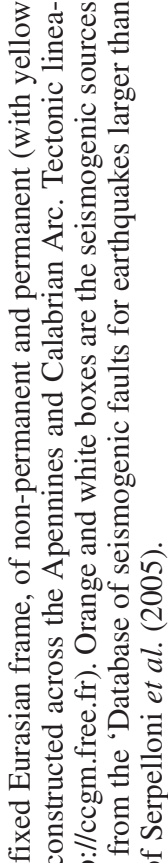

ช

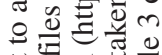

(ํ)

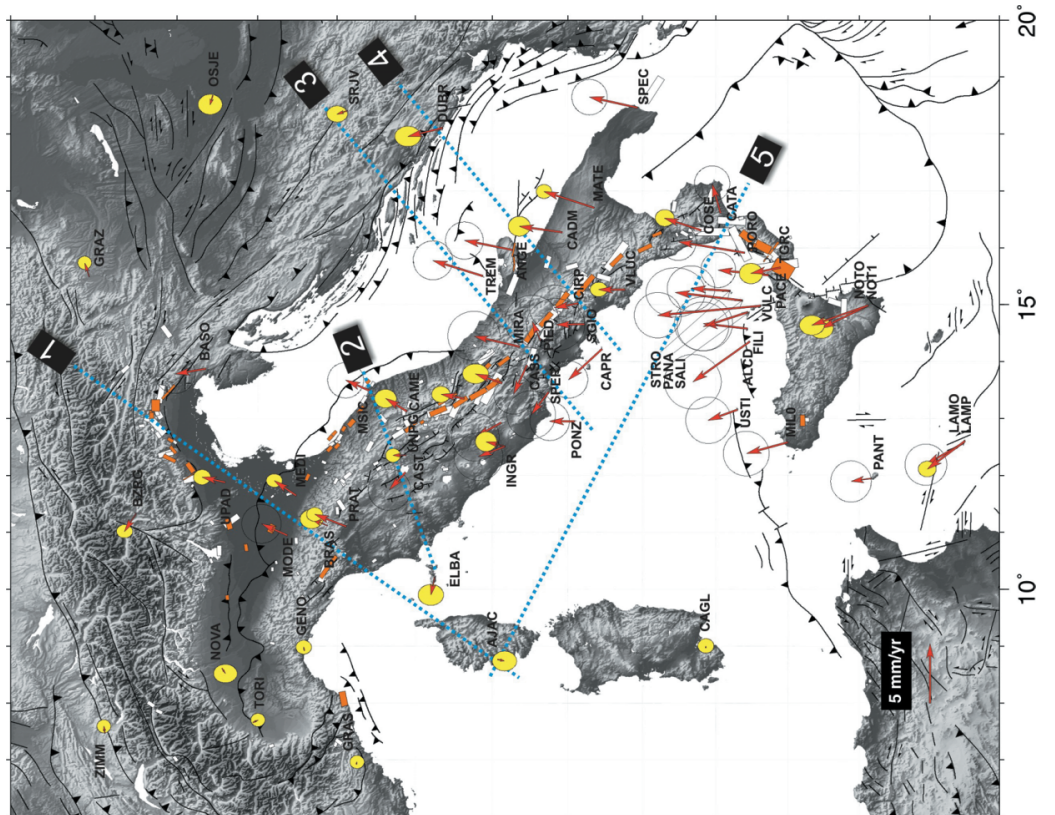

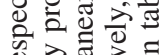

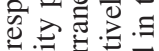

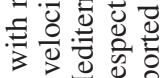

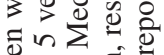

.

किष

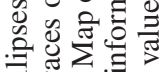

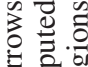

츰

䒹

용

$\infty$

วิ

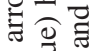

흐응

ㄱ.

긐.马

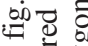

넝.

幽

है -

司远

호을

क्ष

$\Xi . \Xi: 9$

on ?ै

$\exists$ 要

要

氙 䒕

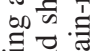

击跔

ฮี

击

얼 중.

웅

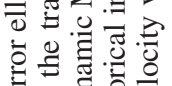

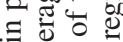

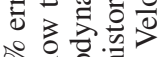

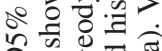

论

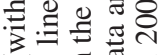

멍 छ

氖

ชิ

จ

플.일

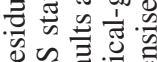

बै

을

至去骂

중 $\frac{2}{3}$

월

뭉ㅎㅀ

荧.

I

寻芯芯

펍ㅁำ

o d on

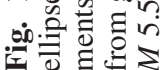

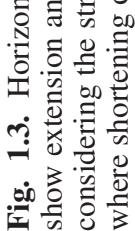


sible, the distribution of the main seismotectonics features (Meletti et al., 2000). We computed the horizontal strain-rate tensor within each region using a common least square procedure and, taking into account the width in the direction of the principal strain axes, we derived the corresponding rates of shortening and elongation (given by the numbers within each areas in fig. 1.3). The computed horizontal principal strain-rates, together with their $1 \sigma$ uncertainties, are listed in table 1.I. It is worth noting that the derived strain rates can be considered as lower bounds, since they may occur more spatially concentrated than resolvable by the GPS data available.

The residual velocity field displays some first order features: most of the GPS stations located west of the Apennines Chain axis display a NNW-ward to NW-ward motion trend, while on the eastern side most of the sites show NNE-ward to NE-ward motion trends. The boundary between these two velocity domains follows the distribution of the seismogenic faults inferred from historical, geophysical and geological data along the chain axis, where the largest earthquakes occurred and elevated topography is present (Valensise and Pantosti, 2001b), suggesting that this lineament is presently working as a major kinematics boundary along the Apennines, separating the two velocity domains (Serpelloni et al., 2005).

In the Northern Apennines, the Marche-Romagna region (subnet no. 9 in fig. 1.3) and the inner sector of the arc in Northern Tuscany (subnet no. 8) display NE-SW extension, at rates of $24 \pm 8$ and $22 \pm 6 \mathrm{~ns} / \mathrm{yr}$, respectively, which provide average extensional rates of 1.9 and $3.3 \mathrm{~mm} / \mathrm{yr}$. Only in the outer sector of the chain (subnet no. 6 and no. 7) is an indication of weak N-S shortening observed, with small strain-rates and average shortening rates below the $1 \mathrm{~mm} / \mathrm{yr}$ level. The Po Plain (subnet no. 4 and no. 5) does not show significant shortening, but moving toward the Southern Alpine domain

Table 1.I. Principal strain-rates and $1 \sigma$ uncertainties computed in the polygonal and triangular regions of fig. 1.2. Positive and negative values represent extension and contraction respectively ( $\varphi$ is the azimuth of $E_{\min }$ ).

\begin{tabular}{ccccccccc}
\hline \hline $\begin{array}{c}\text { Subnet } \\
\text { No. }\end{array}$ & \multicolumn{2}{c}{$\begin{array}{c}\text { Long } \\
\text { Barycentre }\end{array}$} & $\begin{array}{c}E_{\max } \\
(1 / \mathrm{yr})\end{array}$ & $\begin{array}{c}\sigma\left(E_{\max }\right) \\
(1 / \mathrm{yr})\end{array}$ & $\begin{array}{c}E_{\min } \\
(1 / \mathrm{yr})\end{array}$ & $\begin{array}{c}\sigma\left(E_{\min }\right) \\
(1 / \mathrm{yr})\end{array}$ & $\begin{array}{c}\varphi \\
(\mathrm{deg})\end{array}$ & $\begin{array}{c}\sigma(\varphi) \\
(\mathrm{deg})\end{array}$ \\
\hline 1 & 13.56 & 46.42 & $1.0 \mathrm{E}-08$ & $2.1 \mathrm{E}-09$ & $-1.5 \mathrm{E}-08$ & $5.6 \mathrm{E}-09$ & -2 & 7 \\
2 & 12.37 & 45.85 & $4.9 \mathrm{E}-09$ & $3.7 \mathrm{E}-09$ & $-1.2 \mathrm{E}-08$ & $7.1 \mathrm{E}-09$ & 34 & 14 \\
3 & 10.61 & 45.79 & $7.4 \mathrm{E}-09$ & $3.9 \mathrm{E}-09$ & $-6.9 \mathrm{E}-09$ & $4.9 \mathrm{E}-09$ & 22 & 13 \\
4 & 10.78 & 45.01 & $6.1 \mathrm{E}-09$ & $2.8 \mathrm{E}-09$ & $-3.8 \mathrm{E}-09$ & $6.5 \mathrm{E}-09$ & 12 & 20 \\
5 & 12.64 & 44.92 & $1.7 \mathrm{E}-09$ & $3.0 \mathrm{E}-09$ & $-3.9 \mathrm{E}-09$ & $3.8 \mathrm{E}-09$ & 71 & 25 \\
6 & 10.40 & 44.51 & $7.2 \mathrm{E}-09$ & $3.1 \mathrm{E}-09$ & $-5.8 \mathrm{E}-09$ & $5.1 \mathrm{E}-09$ & -7 & 13 \\
7 & 12.07 & 43.99 & $2.9 \mathrm{E}-09$ & $4.0 \mathrm{E}-09$ & $-9.6 \mathrm{E}-09$ & $8.2 \mathrm{E}-09$ & 10 & 21 \\
8 & 10.58 & 43.55 & $2.2 \mathrm{E}-08$ & $5.8 \mathrm{E}-09$ & $-4.8 \mathrm{E}-09$ & $2.9 \mathrm{E}-09$ & 132 & 7 \\
9 & 12.42 & 43.36 & $2.4 \mathrm{E}-08$ & $8.4 \mathrm{E}-09$ & $2.9 \mathrm{E}-09$ & $3.8 \mathrm{E}-09$ & 123 & 12 \\
10 & 12.39 & 41.94 & $1.4 \mathrm{E}-09$ & $2.8 \mathrm{E}-09$ & $-1.6 \mathrm{E}-09$ & $6.4 \mathrm{E}-09$ & 35 & 67 \\
11 & 13.24 & 42.22 & $3.1 \mathrm{E}-08$ & $8.1 \mathrm{E}-09$ & $-3.7 \mathrm{E}-09$ & $2.8 \mathrm{E}-09$ & -24 & 7 \\
12 & 14.10 & 42.61 & $5.4 \mathrm{E}-09$ & $7.7 \mathrm{E}-09$ & $-5.8 \mathrm{E}-09$ & $4.7 \mathrm{E}-09$ & -19 & 23 \\
13 & 14.12 & 40.75 & $5.1 \mathrm{E}-09$ & $3.6 \mathrm{E}-09$ & $-1.4 \mathrm{E}-08$ & $1.7 \mathrm{E}-08$ & 24 & 26 \\
14 & 14.66 & 41.10 & $1.4 \mathrm{E}-08$ & $5.4 \mathrm{E}-09$ & $2.9 \mathrm{E}-09$ & $4.2 \mathrm{E}-09$ & -28 & 17 \\
15 & 15.50 & 41.62 & $2.0 \mathrm{E}-08$ & $9.6 \mathrm{E}-09$ & $-1.1 \mathrm{E}-09$ & $5.8 \mathrm{E}-09$ & 109 & 15 \\
16 & 16.14 & 40.29 & $1.5 \mathrm{E}-08$ & $5.0 \mathrm{E}-09$ & $1.1 \mathrm{E}-09$ & $4.5 \mathrm{E}-09$ & -24 & 14 \\
17 & 17.02 & 39.71 & $1.4 \mathrm{E}-08$ & $3.8 \mathrm{E}-09$ & $-6.9 \mathrm{E}-10$ & $4.2 \mathrm{E}-09$ & 84 & 11 \\
18 & 15.94 & 38.73 & $2.6 \mathrm{E}-08$ & $1.1 \mathrm{E}-08$ & $2.8 \mathrm{E}-10$ & $6.1 \mathrm{E}-09$ & 29 & 14 \\
\hline
\end{tabular}


(subnet n. 1, 2 and 3) strain-rates increase (up to $15 \pm 6 \mathrm{~ns} / \mathrm{yr}$ ) and principal axes rotate in a N-S direction. These values provide preliminary shortening rates of 1.1 and $2.2 \mathrm{~mm} / \mathrm{yr}$, respectively for the Central and Eastern Southern Alps. These observations are in agreement with a tectonic regime driven by the indentation of the Adriatic block.

In the Central Apennines (subnet no. 11) ENE-WSW extension, at a rate of $31 \pm 8 \mathrm{~ns} / \mathrm{yr}$ (about 2.5 $\mathrm{mm} / \mathrm{yr}$ ), is concentrated in a relatively narrow belt, about $80 \mathrm{~km}$ wide, while the Adriatic foredeep and the Southern Tuscany-Latial volcanic area (subnet no. 10 and no. 12, respectively) display negligible or null deformation rates. The Southern Apennines (subnet no. 14 and no. 16) are extending in an ENE-WSW direction, at a rate of $15 \pm 5 \mathrm{~ns} / \mathrm{yr}$ (corresponding to about $1.9 \mathrm{~mm} / \mathrm{yr}$ ). The Campania volcanic district (subnet no. 13) does not display significant deformation, while the Bradanic foredeep (subnet no. 15) is undergoing a NE-SW extension at rates comparable with the ones observed across the chain. The observed extension is in agreement with in situ stress measurements (Montone et al., 1999). Nevertheless, a non-optimal distribution of the GPS stations across the chain cannot provide indications on how the transition from the Southern Apennines domain toward the Gargano domain is presently accommodated.

The transition between the Calabrian Arc and the Southern Apennines domain, where the most evident feature is the faster NE-ward motion of the Apulian stations with respect to the slower NEto E-ward motion of the Calabrian ones, is not well constrained by our velocity solution. The stations CATA and COSE in Calabria and SPEC and MATE on the Apulian block provide about $2.2 \mathrm{~mm} / \mathrm{yr}$ of about N-S extension across the Gulf of Taranto (subnet no. 17). In Calabria (subnet no. 18), due to the non-optimal station distribution, we observe a preliminary strain-rate value of $26 \pm 11 \mathrm{~ns} / \mathrm{yr}$, which, in any case, confirms the NW-SE oriented extension that is taking up at a rate of about 2 $\mathrm{mm} / \mathrm{yr}$.

\subsection{Velocity Profiles across the Apennines Chain and Calabria}

Geodetic strains obtained from the horizontal velocity field represent an important tool for constraining the style of deformation within active seismic belts, but the resulting extensional and shortening rates could be affected by the geometry of the network, and should be considered as averaged values. Nevertheless, fig. 1.3 provides a clear picture of the crustal deformation field along the Apennines, that is dominated by extension about normal to the chain axis. In order to provide more detailed deformation rates across the Apennines, values that could potentially be linked to fault slip rates, in fig. 1.4 we also present some velocity profiles obtained by projecting the residual velocities of fig. 1.2 along five different cross sections crossing the entire chain system.

Profile no. 1 - The velocity profile from AJAC toward GRAZ, across the Northern Apennines, Po Plain and Eastern Alps, shows that most of the extension (about $3.3 \mathrm{~mm} / \mathrm{yr}$ ) is confined to the inner (Tuscany) sector of the chain, between ELBA and PRAT, whereas the region between PRAT and UPAD is undergoing a weak NE-SW shortening, at a rate lower than $1 \mathrm{~mm} / \mathrm{yr}$ level. This tectonic signal is close to the resolution of GPS techniques, and, for this reason, it would need further investigations to be fully confirmed. Nevertheless, the indication that active shortening is present, even if very small, is in agreement with seismicity (Selvaggi et al., 2001; Pondrelli et al., 2002; Chiarabba et al., 2004) and other in-situ stress indicators (Montone and Mariucci, 1999). The area between UPAD and BASO does not display deformation, in agreement with the hypothesis that these two stations belong to the Adriatic microplate, which is rotating counterclockwise with respect to Eurasia (Battaglia et al., 2004; Serpelloni et al., 2005), and is indenting in the Southern Alps, causing significant shortening in this area. The region between BASO and GRAZ display shortening at a rate below the $1 \mathrm{~mm} / \mathrm{yr}$ level.

Profile no. 2 - The velocity profile running across the Northern Apennines from ELBA toward the Marche Region (MSIC) shows that about $2.6 \mathrm{~mm} / \mathrm{yr}$ of ENE-WSW extension is mainly confined between CAST and CAME, in a relatively narrow band (about $80 \mathrm{~km}$ ) where most of the seismic mo- 

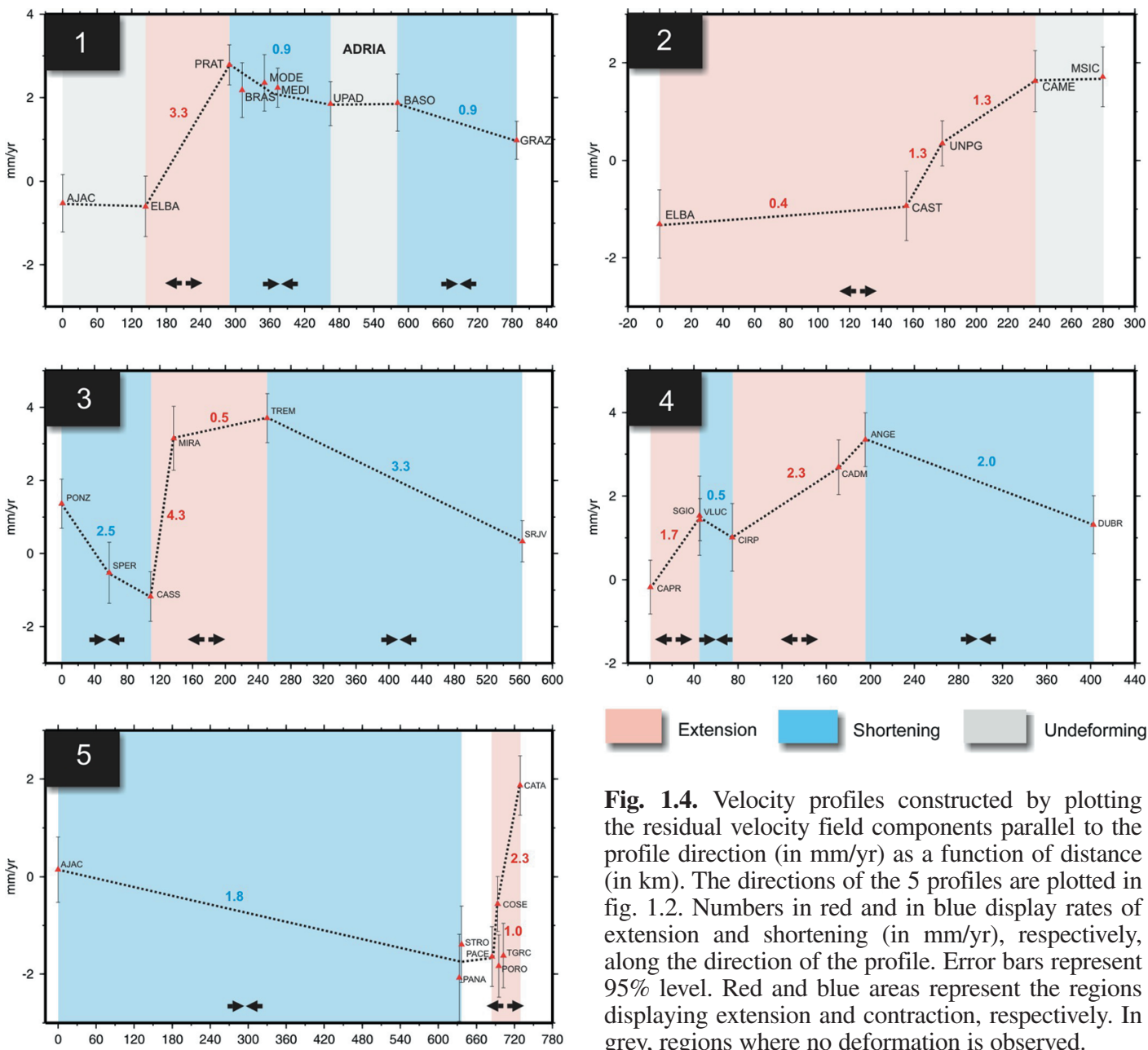

Fig. 1.4. Velocity profiles constructed by plotting the residual velocity field components parallel to the profile direction (in $\mathrm{mm} / \mathrm{yr}$ ) as a function of distance (in $\mathrm{km}$ ). The directions of the 5 profiles are plotted in fig. 1.2. Numbers in red and in blue display rates of extension and shortening (in $\mathrm{mm} / \mathrm{yr}$ ), respectively, along the direction of the profile. Error bars represent 95\% level. Red and blue areas represent the regions displaying extension and contraction, respectively. In grey, regions where no deformation is observed.

ment release is observed (Valensise and Pantosti, 2001b), while no deformation is observed in the outer sector of the chain (between CAME and MSIC). The Tyrrhenian sector of the chain, on the contrary of Profile no. 1, displays a very small extension rate (below $0.5 \mathrm{~mm} / \mathrm{yr}$ ).

Profile no. 3 - The velocity profile running across the southern sector of the Apennines Chain from PONZ to TREM displays a more complex pattern. Significant SW-NE shortening is observed in its Tyrrhenian sector (from PONZ to CASS), where thrust events have been recorded in the past (i.e. the Anzio-Nettuno 1919 earthquake; Tertulliani et al., 2003). Large extension (more than 4 $\mathrm{mm} / \mathrm{yr}$ ), NE-SW oriented, is occurring between the $\sim 30 \mathrm{~km}$ separating CASS and MIRA, with consequently large strain-rates, up to $140 \mathrm{~ns} / \mathrm{yr}$. It is worth noting that this profile crosses a very complex tectonic frame, where the transition from the Southern and Northern Apenninic arcs occurs (marked by the about N-S Ortona-Roccamoffina lineament), and where E-W lineaments, like the Mattinata Fault (a major active strike-slip feature cutting across the Gargano promontory) are present, and have also been associated with recent earthquakes (i.e. the 31 October 2002 Molise earthquake). For this 
reason, the deformation pattern in this area should not be characterized by a main SW-NE extension, but should be complicated by trans-tensional motions. The relative motion between CASS and MI$\mathrm{RA}$, in fact, could also been accommodated along an E-W system (westward prosecution of the Mattinata Fault) with about $2.8 \mathrm{~mm} / \mathrm{yr}$ of right lateral motion. No significant relative motion between MIRA and TREM is observed. These two sites, in fact, display similar velocities, suggesting that the motion of MIRA could be linked to the kinematics of Adria, well depicted by the NE-ward drift of the Apulian block. Between TREM and SRJV about $3.3 \mathrm{~mm} / \mathrm{yr}$ of NW-SW shortening is observed, which is likely to be accommodated along the Dinaric seismic belt and is governed by the counterclockwise rotation of Adria.

Profile no. 4 - This profile crosses the Irpinia region, but the lack of GPS stations on the Adriatic side of the chain does not allow any direct measurement of where strains are accumulating at a more local scale. The data available provide a regional extension of about $2.3 \mathrm{~mm} / \mathrm{yr}$ that is taking up across the whole Southern Apennines Range, between CIRP and TREM. Between ANGE and DUBR there is about $2.0 \mathrm{~mm} / \mathrm{yr}$ of NE-SW shortening, which, as for Profile no. 4, is connected to the Adriatic kinematics.

Profile no. 5 - This velocity profile crosses the Tyrrhenian Sea in a NW-SE direction, toward Calabria, displaying no evidence of the back arc spreading that characterized the evolution of the Tyrrhenian Basin (Kastens and Mascle, 1990). NW-SE shortening is observed, in fact, between the Corsica-Sardinia block, which is behaving as a rigid part of the Eurasian Plate, and stations on the Aeolian Arc. However, the lack of stations avoid any further speculation on where the shortening is accommodated, or if other tectonic processes are taking up in the Tyrrhenian Sea. The structural and kinematic complexity of the Southern Tyrrhenian has been constrained by GPS and seismic data (Hollenstein et al., 2003; Pondrelli et al., 2004; Serpelloni et al., 2005) which show that its current kinematics is characterized by two different regimes, separated by a major $\sim \mathrm{N}-\mathrm{S}$ tectonic lineament (the Aeolian-Maltese fault system), with $\sim \mathrm{N}-\mathrm{S}$ shortening and NW-SE extension west and east of the Central Aeolian islands, respectively. This velocity cross-section describes what is going on east of this major lineament, and shows that extension is mostly accommodated in Calabria, where more than $2 \mathrm{~mm} / \mathrm{yr}$ are taking up between COSE and CATA.

\subsection{Conclusions}

In this paper we used the velocity field reported in Serpelloni et al. (2005), obtained by merging in a self-consistent velocity solution continuous and non-permanent GPS observations spanning the 1991-2002 time interval, to provide further quantitative constraints to the active tectonic processes occurring along the Apennines Chain. We computed horizontal strain-rates within polygonal and triangular regions along the Apennines and in Calabria, deriving mean extension and shortening rates. We have also drawn five velocity profiles across the same area, which provide direct measurements of more localized deformation rates across active seismic belts, that can be related to active fault systems. We observed that the lineament of seismogenic faults, striking about parallel to the chain axis, appears to behave as a major kinematic boundary in separating two different velocity domains: an Adriatic one, with NE- to NNE-ward motion trends, and a Tyrrhenian one, with NW- to NNW-ward motion trends.

GPS data clearly show that the Apennines are undergoing a regional $\sim$ NE-SW extension, in agreement with seismological, geological and classic geodetic observations. The rates of extension along the southern and central sectors of the chain are between $\sim 1.8$ and $\sim 2.5 \mathrm{~mm} / \mathrm{yr}$, respectively, and deformation appears to be mainly confined to a relatively narrow belt, within which the largest part of the seismic moment release is observed and most of the seismogenic faults are located. In the Southern Apennines, across the Irpinia region, we measured NE-SW extension occurring at a rate of about $2.3 \mathrm{~mm} / \mathrm{yr}$. The area of transition between the Southern and Northern Apennine arcs (i.e. Southern 
Latium and Molise regions), instead, displays a more complicated deformation pattern, where rightlateral strike slip motion occurring along E-W trending faults, at a rate up to $2.8 \mathrm{~mm} / \mathrm{yr}$, could explain the high local strains observed.

In the Northern Apennines, regional extension at $\sim 3.3 \mathrm{~mm} / \mathrm{yr}$ appears to be mainly confined to its inner sector, while small SW-NE to N-S shortening is present in its outer sector. The two velocity profiles across the Northern Apennines show that most of the regional extension observed is currently taking up in its northern-western sector (Northern Tuscany), while moving toward the UmbriaMarche region, extension is more localized in a narrow band. They also show that the outer sector of the chain displays smaller deformation rates, and indications of active shortening (at rates below the $1 \mathrm{~mm} / \mathrm{yr}$ level) are observed only in the outer Northern Apennines, and mainly in the Emilia-Romagna Region.

While there is no evidence of active NW-SE back-arc spreading currently occurring in the Tyrrhenian Basin, we measured relatively higher NW-SE extension (more than $2 \mathrm{~mm} / \mathrm{yr}$ ) in Calabria; nevertheless, this value must be considered preliminary given the poor geometry of the geodetic network available.

The deformation rates observed in the rest of the peri-Adriatic region (i.e. Southern Alps and Dinarides) are related to the counter-clockwise rotation of the Adriatic microplate with respect to Eurasia, displaying values of SW-NE shortening along the Dinaric front ranging between 2 and $3.3 \mathrm{~mm} / \mathrm{yr}$, and rates of N-S to SW-NE shortening in the Eastern Alpine between 1 and $2 \mathrm{~mm} / \mathrm{yr}$.

\section{ACKNOWLEDGEMENTS}

This work was partially funded by the Italian Space Agency (ASI-ARS contract), the Ministry of Public Education, University and Research and the Department of Civil Protection. We are thankful to Prof. Enzo Boschi who supported this research and to all individuals and institutions which contributed in the GPS data collection. The maps have been created using the Generic Mapping Tools (GMT) software (Wessel and Smith, 1995).

\section{REFERENCES}

Altamini, Z., P. Sillard and C. Boucher (2002): ITRF2000: A new release of the international terrestrial reference frame for Earth Science applications, J. Geophys. Res., 107 (B10), 2214, doi: $10.1029 / 2001$ JB000561.

ANDERSON, H. and J. JACKSON (1987): Active tectonics of the Adriatic region, Geophys. J. R. Astr. Soc., 91, 937-983.

Anzidei, M., P. Baldi, A. Pesci, A. Esposito, A. Galvani, F. Loddo and P. CRistofoletti (2005): Geodetic deformation across the Central Apennines from GPS data in the time span 1999-2003, Ann. Geophysics, 48 (2), 259-271.

Battaglia, M., M.H. Murray, E. Serpelloni and R. Burgmann (2004): The Adriatic region: an independent microplate within the Africa-Eurasia collision zone, Geophys. Res. Lett., 31, L09605, doi: 10.1029/2004GL019723.

BlewitT, G., Y. Bock and G. Gendt (1993): Regional clusters and distributed processing, in IGS Analysis Center Workshop, Ottawa, Canada, 62-91.

Chiarabba, C., L. Jovane and R. Di Stefano (2004): A new view of Italian seismicity using 20 years of instrumental recordings, Tectonophysics, 395, 251-268.

D’agostino, N., R. Giuliani, M. Mattone and L. Bonci (2001): Active crustal extension in the Central Apennines (Italy) inferred from GPS measurements in the interval 1994-1999, Geophys. Res. Lett., 28 (10), 2121-2124. 
Dewey, J.F., M.L. Helman, E. Turco, D.H.W. Hutton and S.D. Knott (1989): Kinematics of the Western Mediterranean, in Alpine Tectonics, edited by M.P. Coward, D. DiETRICH and R.G. PARK, Geol. Soc. London, Spec. Publ., 45, 265-283.

Dixon, T.H., M. Miller, F. Farina, H. WANG and D. Johnson (2000): Present-day motion of the Sierra Nevada block and some tectonic implications for the basin and range province, North American Cordillera, Tectonics, 19 (1), 1-24.

Dong, D., T.A. HERring and R.W. KING (1998): Estimating regional deformation from a combination of space and terrestrial geodetic data, J. Geod., 72, 200-214.

Dong, D., P. FAnG, Y. Bock, M.K. Cheng and S. MiYAzAKi (2002): Anatomy of apparent seasonal variation from GPS-derived site position, J. Geophys. Res., 107, 10.1029/2001JB000573.

HERring, T.A. (2000): GLOBK: Global Kalman Filter VLBI and GPS Analysis Program Version 10.0, Massachusetts Institute of Technology, Cambridge.

Hollenstein, C.H., H.G. Kahle, A. Geiger, S. Jenny, S. Goes and D. Giardini (2003): New GPS constraints on the Africa-Eurasia Plate boundary zone in Southern Italy, Geophys. Res. Lett., 30 (18), 1935, doi: 10.1029/2003GL017554.

HunStAD, I. and P. ENGLAND (1999): An upper bound on the rate of strain in the Central Apennines, Italy, from triangulation measurements between 1869 and 1963, Earth Planet. Sci. Lett., 169, 261-267.

Hunstad, I., G. Selvaggi, N. D’Agostino, P. England, P. Clarke and M. Pierozzi (2003): Geodetic strain in peninsular Italy between 1875 and 2001, Geophys. Res. Lett., 30 (4), 1181, doi: 10.1029/2002GL016447.

KAstens, K.A. and J. MAscle (1990): The geological history of the Tyrrhenian Sea: an introduction to the scientific results of ODP Leg 107, Proc. Ocean Drill. Progr. Sci. Results, 107, 3-26.

KING, R.W. and Y. Bock (2000): Documentation for GAMIT GPS Analysis Software Version 10.01, Massachusetts Institute of Technology and Scripps Institution of Oceanography.

Mantovani, E., D. Albarello, C. Tamburelli and D. Babbucci (1996): Evolution of the Tyrrhenian Basin and surrounding regions as a result of the Africa-Eurasia convergence, J. Geodyn., 21, 35-72.

MaO, A., C.G.A. HARrison and T.H. DiXon (1999): Noise in GPS coordinate time series, J. Geophys. Res., 104, 2797-2816.

Meletti, C., E. Patacca and P. Scandone (2000): Construction of a seismotectonic model: the case of Italy, Pure Appl. Geophys., 157, 11-35.

Montone, P. and M.T. MARIUCCi (1999): Active stress along the NE external margin of the Apennines: the Ferrara Arc, Northern Italy, J. Geodyn., 28, 251-265.

Montone, P., A. Amato and S. Pondrelli (1999): Active stress map of Italy, J. Geophys. Res., 104, 25,595-25,610.

Pondrelli, S., A. Morelli, G. Ekström, S. MazZA and E. Boschi (2002): European-Mediterranean regional centroid-moment tensors: 1997-2000, Phys. Earth Planet. Int., 130, 71-101.

Pondrelli, S., C. Piromallo and E. SerPelloni (2004): Convergence versus retreat in Southern Tyrrhenian Sea: insights from kinematics, Geophys. Res. Lett., 31, L0661, doi: 10.1029/2003GL019223.

SElvaGGi, G. (1998): Spatial distribution of horizontal seismic strani in the Apennines from historical earthquakes, Ann. Geofis., 41 (2), 241-251.

SelvagGi, G. and A. Amato (1992): Subcrustal earthquakes in the Northern Apennines (Italy): evidence for a still active subduction?, Geophys. Res. Lett., 19 (21), 114-127.

Selvaggi, G., F. Ferulano, M. Di Bona, A. Frepoli, R. Azzara, A. Basili, C. Chiarabba, M. CiacCio, F. Di Luccio, F.P. Lucente, L. Margheriti and C. Nostro (2001): The $M_{w}=5.4$ Reggio Emilia 1996 earthquake: active compressional tectonics in the Po Plain, Italy, Geophys. J. Int., 144, 1-13.

Serpelloni, E., M. Anzidei, P. Baldi, G. Casula, A. Galvani, A. Pesci and F. Riguzzi (2001): Geodetic deformations in the Central-Southern Apennines (Italy) from repeated GPS surveys, Ann. Geofis., 44 (3), 627-647. 
Serpelloni, E., M. Anzidei, P. Baldi, G. Casula, A. Galvani, A. Pesci and F. Riguzzi (2002): Combination of permanent and non-permanent GPS networks for the evaluation of the strain-rate field in the Central Mediterranean area, Boll. Geofis. Teor. Appl., 43, 195-219.

Serpelloni, E., M. Anzidei, P. BAldi, G. Casula and A. Galvani (2005): Crustal velocity and strainrate fields in Italy and surrounding regions: new results from the analysis of permanent and nonpermanent GPS networks, Geophys. J. Int., 161 (3), 861-880.

Tertulliani, A., A. Rossi and R. Di Giovanbattista (2003): Reappraisal of the 22 October 1919 Central Italy earthquake, Bull. Seismol. Soc. Am., 93, 1928-1305.

VAlensise, G. and D. PANTOSTI (2001a): The investigation of potential earthquake sources in peninsular Italy: a review, J. Seismol., 5, 287-306.

VAlensise, G. and D. PAntosti (2001b): Database of potential sources for earthquakes larger than $M$ 5.5 in Italy, Ann. Geofis., 44 (suppl. to no. 4), pp. 180 with CD-ROM.

Viti, M., D. Albarello and E. Mantovani (2001): Classification of seismic strain estimates in the Mediterranean region from a 'bootstrap' approach, Geophys. J. Int., 146, 399-415.

WeSSEL, P. and W.H.F. SMITH (1995): New version of the generic mapping tools released, EOS Trans. Am. Geophys. Un., 76, 329.

Westaway, R. (1992): Seismic moment summation for historical earthquakes in Italy: tectonic implications, J. Geophys. Res., 97, 15,437-15,464. 